\title{
The application of pyrite chemistry to hydrothermal base metal deposits: An example of Irish-type $\mathbf{Z n}-\mathbf{P b}$ mineralization
}

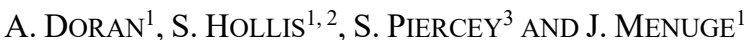

${ }^{1}$ UCD School of Earth Sciences \& Irish Centre for Research in Applied Geosciences (iCRAG), University College

Dublin, Belfield, Dublin 4, Ireland.

(aileen.doran@icrag-centre.org).

${ }^{2}$ Geological Survey Ireland, Haddington Road, Beggars Bush, Dublin 4, Ireland.

${ }^{3}$ Department of Earth Sciences, Memorial University of Newfoundland, 300 Prince Philip Drive, St. John's, Newfoundland, Canada A1B 3X5.

Globally, mineral chemistry studies have effectively been used to enhance understanding of how economic deposits, such as SEDEX and MVT type mineralization, form. Pyrite chemistry is considered a powerful tool in the understanding of ore deposit genesis, as it can record the entire evolution of a system, along with any compositional changes in the precipitating fluid. These studies have also been used to define geochemical halos surrounding mineralization, by focusing on specific trace element variations (e.g. Mo, Ag).

Recent pyrite trace element analyses from the Lisheen deposit, Ireland, has looked at variations at several different scales, including; orebody against the surrounding subeconomic mineralization, stratigraphic, grain-scale and nanoscale variations. Initial studies have focused on the Island Pod orebody in the north of the deposit, but a deposit scale investigation across the wider mine area is currently in progress.

Island Pod trace element analysis has shown that mean pyrite concentrations of $\mathrm{Co}, \mathrm{Ni}, \mathrm{Tl}$, and $\mathrm{As}$ are 40-80\% higher in the ore zone than the surrounding sub-economic halo. Pyrite grain-scale variations have also been identified, providing insights into the fluid evolution of the system. Systematic increases in Co and As from cores to rims in zoned pyrites are commonplace, confirming precipitation from distinct pulses in a continuously evolving system. Grain-scale variations have also allowed us to investigate the inclusion of nanoparticles versus incorporation into the crystal lattice. For pyrite, the inclusion of $\mathrm{Tl}$ appears to be dependent on the presence of As ( 0.79 positive correlation), with both substituting into the crystal lattice in place of S.

Our research reinforces the concept that pyrite mineral chemistry can be used as an effective vector towards mineralization in Irish-type base metal deposits, in addition to tracking the fluid evolution of such systems. 